\title{
Is there more to life than 'spit sucking'*? \\ 西
}

\section{Dental nurses Geraldine Birks and} Julia Armstrong say that there has never been a better time to progress in your
career - and they are perfect examples.

\section{s experienced dental nurses can we reach further? Can we develop into more? Or do we accept that we are destined to work efficiently chairside for} the rest of our careers? Of course there is that old-fashioned option to leave what we are familiar with and embark upon hygiene and therapy. However, there is more without abandoning dental nursing, and in today's General Dental Council (GDC) registered professional environment, opportunities for our professions are in abundance.

Our own journeys began in 2002 when, after qualifying as dental nurses, our careers took different routes yet brought us to the same destination.

Once qualified, opportunities presented themselves for both of us. Julia was encouraged to progress immediately into teaching: qualifying as a further education teacher, then as an assessor and internal verifier. Geraldine developed her interest in education, dental sedation and oral health, qualifying through City \& Guilds and the National Examining Board for Dental Nurses (NEBDN) in these specialties. What we both found was a passion for education, for developing - not only ourselves but inspiring others.

In 2006 two positions were advertised as a new initiative at the Yorkshire and Humber Deanery in Leeds (now known as Health Education England, Yorkshire and Humber Office) to assist dental nurses during the transition to GDC registration. It was here that we met: first as colleagues then becoming close friends that share ambitions, lifelong learning and a passion to educate and develop others.

A seed was sown during an appraisal in 2009 to undertake the Bachelor of Arts Degree in Education and Training. We questioned our

abilities, our availability of time (given we both have children and families to consider) and reviewed the benefits to our job roles.

We made endless 'pros and cons' lists, spoke to other professionals who had embarked down such a path, and encouraged and supported each other to take the first tentative step towards enrolment. As we live in different areas of the county, each of us attended different evening courses whilst enrolling at the same university. We would like to report that it was easy and that we sailed through three years without sweat and tears, however, this was certainly not the case. One factor for this is that we both have other dental positions running alongside our Deanery roles. Julia continued to work with initial dental nurse training and became involved in the Faculty of General Dental Practitioners (UK) (FGDP[UK]) as a member of the Yorkshire Board. Geraldine was appointed to the GDC's Fitness to practise Investigating Committee in 2009, three years after that to also become a Quality Assurance Educational Inspector of UK dental schools. Without the support of each other and our families we could not have achieved the success we have. The third year of the degree is the 'honours' year ... we so very nearly gave up! We remember a discussion over coffee about life before the degree when we spent time enjoying weekends, before they became obliterated and

GERALDINE (pictured left) My name is Geraldine Birks and I entered the profession in 2000 afer moving to Yorkshire with my husband. When I qualified in 2002 I didn't have enough chairside experience to claim my NEBDN badge.

\section{?}

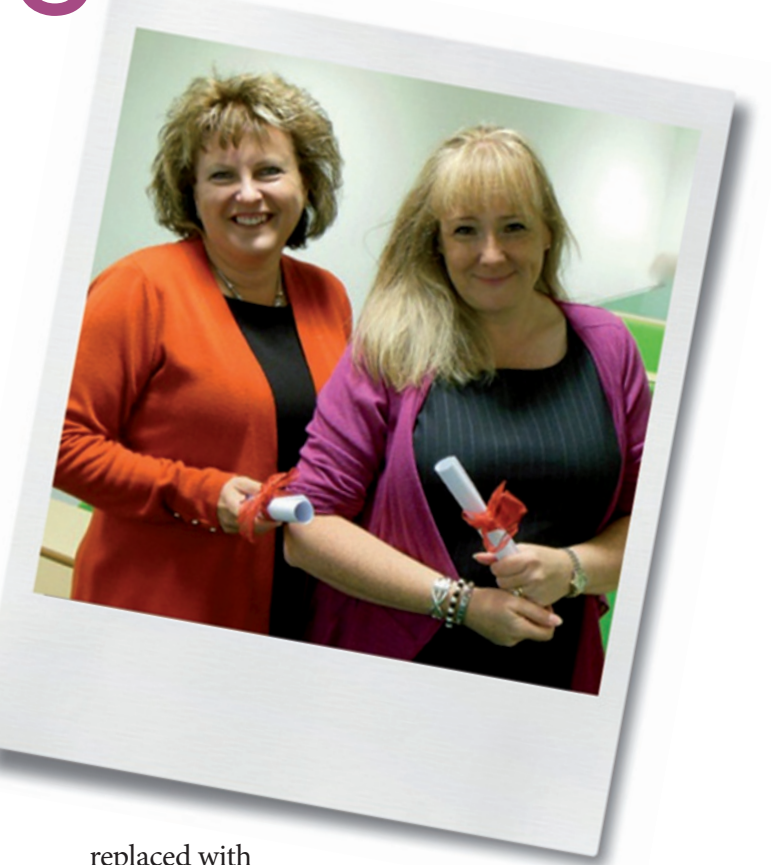

replaced with

study and word counts.

Graduating with honours in November 2013 has been the pinnacle of our dedication and hard work. During this period of time, we have written and developed a number of extended duty dental nursing competencies in Fluoride Varnish Application and Dental Impression Taking. As a team, we deliver education and training across the North of England: something we enjoy and are passionate about. Our varied skills and experiences have enabled us to produce and deliver a wide variety of verifiable CPD courses to all dental care professional categories, Foundation year 1 and 2 dentists and general dental practitioners.

With new GDC Standards and an expanded scope of practice with direct access there has never been a better time to be a dental educator. We love our jobs and count ourselves very fortunate to work within dentistry and education.

*term used by the authors of this article!
JULIA (pictured right)

My name is Julia Armstrong and I have been dental nursing since 1984 when I drifted into the role during my 'year out' before going to university. Eighteen years into my 'year out' I qualified as a dental nurse. 